\title{
Síndrome de Gardner: relato de caso e breve revisão da literatura
}

\author{
Gardner Syndrome: case report and brief review of the literature
}

Isabela Azevedo Nicodemos da $\mathrm{Cruz}^{1}$, Fernanda Sasaki Vergílio ${ }^{2}$, Lorena Luryann Cartaxo da Silva ${ }^{1}$, Gabriela Azevedo Nicodemos da $\mathrm{Cruz}^{3}$

\begin{abstract}
RESUMO
Modelo do estudo: Relato de caso. Importância do problema e comentários: A Síndrome de Gardner trata-se de uma variante da Polipose Adenomatosa Familiar (PAF), com associação de pólipos gastrointestinais, tumores de partes moles e tumores ósseos. É uma desordem rara e o diagnóstico precoce é crucial para redução da morbimortalidade. O presente estudo relata um caso de Síndrome de Gardner com seus achados clínicos e radiológicos, além de apresentar breve revisão da literatura.
\end{abstract}

Palavras-chave: Síndrome de Gardner. Polipose Adenomatosa do Cólon. Polipose Intestinal. Fibroma. Osteoma. Cisto Epidérmico. Relatos de Casos.

\begin{abstract}
Type of study: Case report. Relevance and comments: Gardner Syndrome is a variant of Familial Adenomatous Polyposis (FAP), with the association of gastrointestinal polyps, soft tissue tumors and bone tumors. It is a rare disorder and early diagnosis is crucial to reduce its morbimortality. The present report illustrates a case of Gardner Syndrome with its clinical and radiologic features, as well as a brief review of the literature.
\end{abstract}

Keywords: Gardner Syndrome. Adenomatous Polyposis Coli. Intestinal Polyposis. Fibroma. Osteoma. Epidermal Cyst. Case Reports.

\section{Introdução}

A Síndrome de Gardner, descrita por Gardner em 1951, é uma doença autossômica rara determinada pela mutação do gene adenomatous polyposis coli (APC), considerada uma variante da Polipose Adenomatosa Familiar (PAF), esta última caracteri- zada por múltiplos pólipos adenomatosos colôni$\cos ^{1,2,3}$ Associando a prevalência destas duas entidades, relata-se acometimento de cerca de 2,29$3,2 / 100.000$ pessoas, ${ }^{4}$ sem diferença significativa entre os sexos.

Além dos pólipos colônicos presentes na PAF, a síndrome de Gardner apresenta achados extrain-
1. Residentes do Serviço de Radiologia e Diagnóstico por Imagem do Hospital do Servidor Público Estadual de São Paulo (HSPE - SP).

2. Médica assistente da equipe de Tórax do HSPE - SP

3. Acadêmica do curso de Medicina da Universidade Federal de Pernambuco (UFPE)
CORRESPONDÊNCIA: Isabela Azevedo Nicodemos da Cruz Hospital do Servidor Público Estadual de São Paulo (HSPE) Rua Pedro de Toledo, 1800 - Vila Clementino CEP: 04039-000 - São Paulo - SP,

Recebido em 12/05/2017 Aprovado em 02/10/2017 
testinais: tumores fibrosos de partes moles e tumores ósseos, historicamente descritos como "tumores moles" e "tumores duros". ${ }^{5}$

Relata-se, no presente artigo, um caso de Síndrome de Gardner e breve revisão das suas particularidades com foco nas manifestações extraintestinais.

\section{Relato de Caso}

D.A., 37 anos, feminino, apresentou-se ao serviço de Gastroenterologia em 2009 para investigação de queixas de refluxo e epigastralgia previamente estudadas em outro serviço.

A paciente relatava surgimento de massa cervical à direita desde a infância, com crescimento progressivo e sem repercussões clínicas até a adolescência, quando apresentou quadro de parestesia em membro superior direito. Em 1993, foi realizada ressecção parcial da massa, cujo estudo anatomopatológico evidenciou fibrose com acentuada deposição de colágeno, sem atipias.

Ao exame físico, foi identificado endurecimento da região cervical posterior direita, indolor à palpação, sem sinais flogísticos, com aspecto de espessamento de pele, não sendo identificada massa delimitada. Não foram identificados outros achados em partes moles ao exame e a anamnese não evidenciou antecedentes pessoais ou familiares de relevância clínica.

Ademais, a paciente referiu aparecimento de massas indolores nas regiões mandibulares bilateralmente, com aumento progressivo e lento de suas dimensões, desde os 13 anos. Raspagem diagnóstica em 2006 apresentou histologia indicativa de osteoma.

Em 2009, paciente iniciou quadro de refluxo e vômitos. Foram identificados múltiplos pólipos gástricos, duodenais e colônicos e retais à endoscopia digestiva alta, colonoscopia e retossigmoidoscopia. A polipectomia e o estudo patológico confirmaram diagnóstico de pólipos gástricos de glândulas fúndicas e pólipos adenomatosos tubulares gastrointestinais sem atipias.
Diante da identificação da polipose gastrointestinal múltipla, associada a tumor de partes moles e osteoma de mandíbula, a hipótese de Síndrome de Gardner foi aventada e a paciente passou a ser acompanhada anualmente com exame clínico, endoscópico e anatomopatológico.

Em 2011, biópsia de pólipo ileal evidenciou adenoma tubular com displasia epitelial de baixo grau. A partir de 2012, em biópsias das lesões colônicas e retais foram diagnosticados adenomas tubulares e tubulovilosos com atipias leves e displasia de baixo grau. (Figura 1 - Biópsia do reto, evidenciando adenoma tubular com atipias leves)
Figura 1: Biópsia do reto, coloração hematoxilina-eosina, evidenciando adenoma tubular com atipias leves.
A paciente foi internada em pelo menos duas ocasiões para realização de colectomia profilática. Entretanto, devido à multiplicidade dos pólipos gástricos e de intestino delgado associados, foi optado pela equipe médica da Gastroenterologia pela não realização do procedimento.

Tomografia computadorizada (TC) dos seios da face em 2016 evidenciou imagens nodulares escleróticas com contornos lobulados nos seios esfenoidais medindo até $1,3 \mathrm{~cm}$ no maior eixo, nos ramos mandibulares, maior à esquerda medindo $1,0 \mathrm{~cm}$, e no etmoide anterior, devendo representar múltiplos osteomas. (Figura 2 - Tomografia computadorizada de seios da face evidenciando osteomas em ramos mandibulares)

Na mesma data, a paciente foi submetida a tomografia computadorizada do tórax, que evidenciou volumosa formação expansiva sólida e hete- 


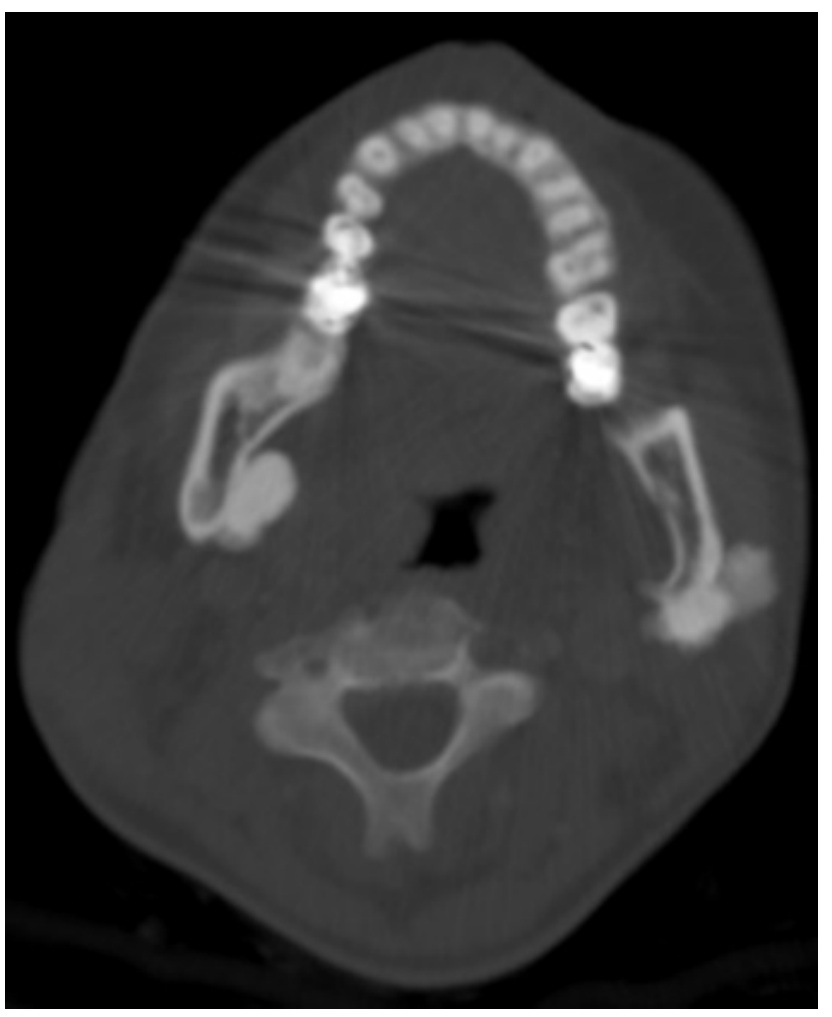

Figura 2: Tomografia computadorizada de seios da face evidenciando osteomas em ramos mandibulares

rogênea na região supraclavicular direita, medindo $10,5 \times 8,2 \mathrm{~cm}$ nos seus maiores eixos axiais, envolvendo os três primeiros arcos costais direitos, que apresentavam remodelamento ósseo. A lesão re- duzia o calibre das veias braquicefálica, subclávia e jugular interna direitas, determinando sinais de síndrome da veia cava superior. A artéria subclávia direita apresentava-se envolvida pela massa, porém de calibre preservado. (Figura 3 - Tomografia computadorizada do tórax, com massa na região supraclavicular à direita).

Na Ressonância Magnética do pescoço em 2016, a mesma massa foi identificada, caracterizada por tecido com baixo sinal em todas as sequências, de permeio às fibras musculares dos músculos paravertebrais locais, sem apresentar realce com contraste paramagnético.

A história clínica da paciente, associada às características da massa cervical, com caráter expansivo e de crescimento lento e progressivo, permitiu diagnóstico presuntivo de tumor desmóide.

À tomografia computadorizada de abdome em 2016, foram identificados os pólipos colônicos difusos, o maior no ângulo esplênico medindo $0,9 \mathrm{~cm}$, além de múltiplas lesões osteocondensantes em ossos ilíacos, sacro e vértebras toracolombares, podendo corresponder a osteomas.

Paciente procurou o serviço de dermatologia em 2016 devido a lesão superficial em quarto quirodáctilo direito. Ao exame clínico, evidenciou-se nódulo móvel e elástico acometendo tecidos superficiais do dedo. Foi realizada biópsia, confirmando diagnóstico de cisto epidermóide.

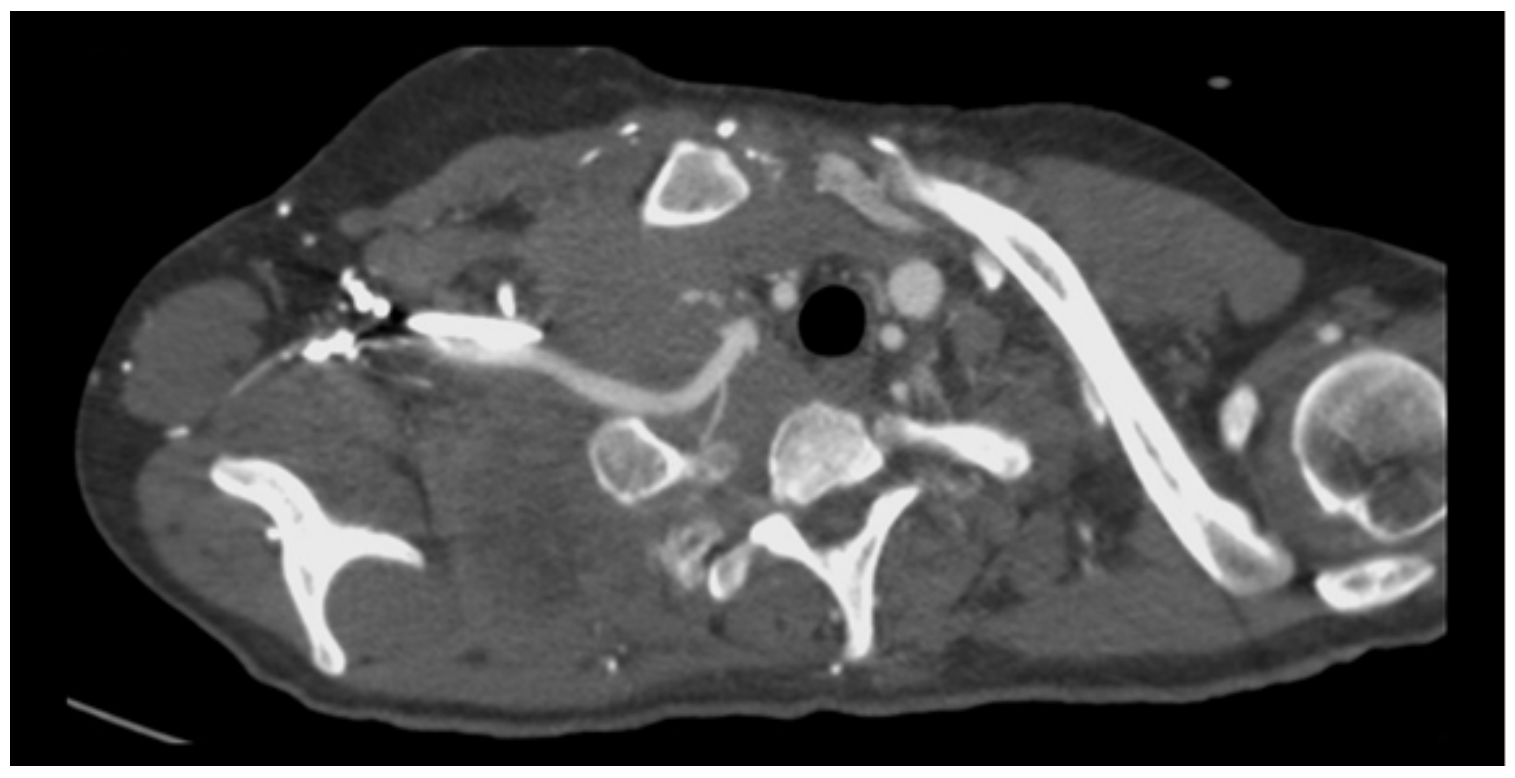

Figura 3 : Tomografia computadorizada do tórax, com massa na região supraclavicular à direita 
Em junho de 2017, a paciente foi submetida a controle com ressonância magnética de pescoço e tórax da lesão na região supraclavicular, que evidenciaram estabilidade das dimensões da formação expansiva, caracterizada por aspecto heterogêneo com predomínio de hipossinal nas sequências ponderadas em T1 e T2. Identificou-se discreto realce homogêneo ao meio de contraste, sem sinais de restrição à difusão. A formação mantinha contato com os corpos vertebrais adjacentes e com a parede posterolateral do esôfago proximal, além de determinar sinais de síndrome da veia cava superior, com proeminência vascular na parede torácica direita. Além disso, foram identidicados múltiplos focos de baixo sinal em T1 e T2 nos corpos vertebrais torácicos e arcos costais, provavelmente osteomas. (Figuras 4 e 5 - Ressonância Magnética do Pescoço, com massa mal delimitada com baixo sinal em todas as sequências e realce homogêneo ao meio de contraste paramagnético na sequência THRIVE).

A paciente foi encaminhada ao ambulatório de aconselhamento genético e mantém acompanhamento ambulatorial, sem programação cirúrgica.

\section{Discussão}

A Síndrome de Gardner é uma variante da polipose adenomatosa familiar (PAF), cursando com associação de pólipos intestinais disseminados e tumores ósseos e de partes moles. Estima-se que $50 \%$ dos pacientes com PAF apresentem manifestações extraintestinais, usualmente subclínicas. ${ }^{6}$

A Síndrome FAP-Gardner é associada a alteração genética no braço longo do cromossomo 5 (5q21-22), denominado adenomatous polyposis coli

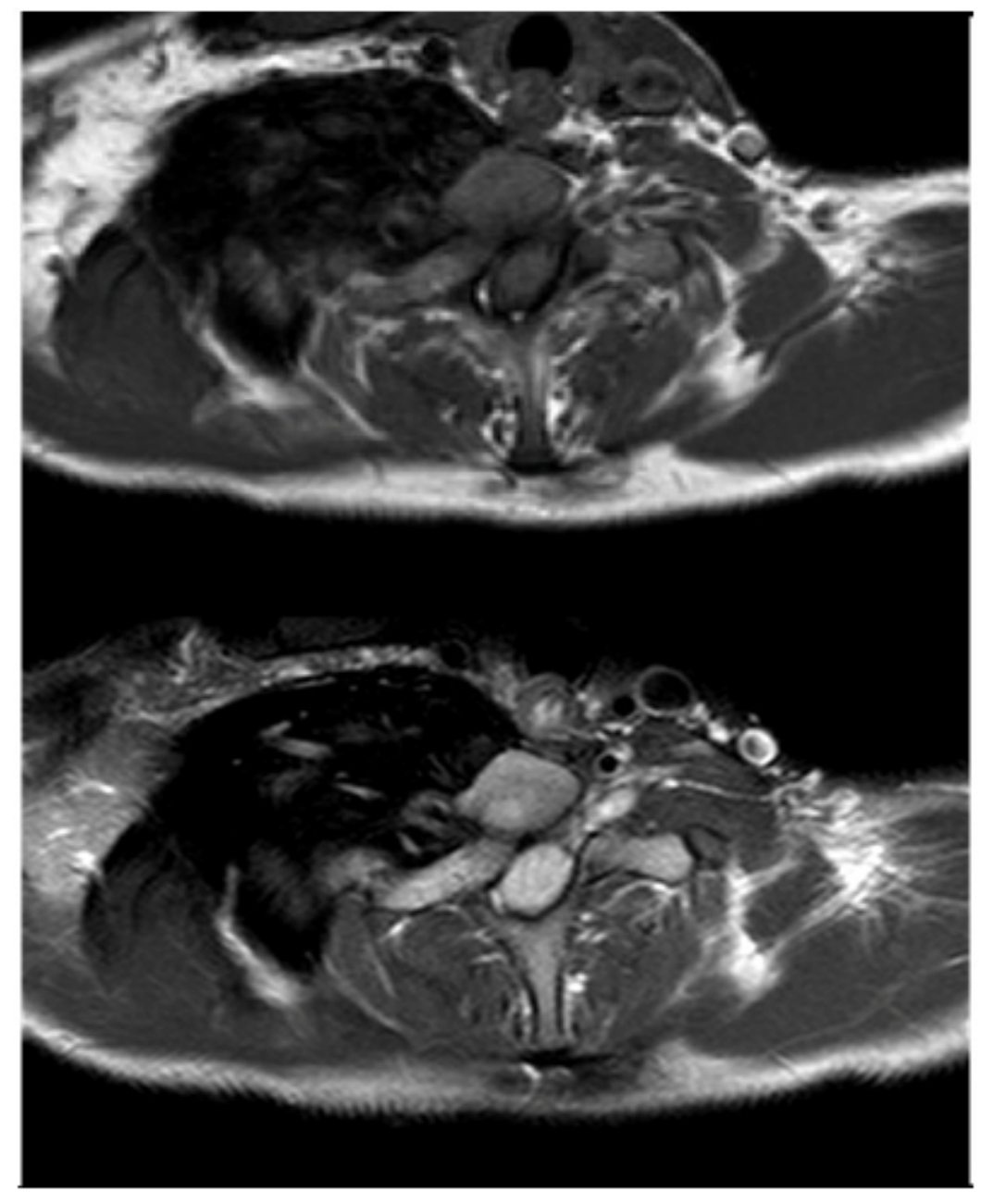

Figura 4: Ressonância magnética do pescoço, evidenciando massa com baixo sinal em T1 e T2 na região cervical à direita. 


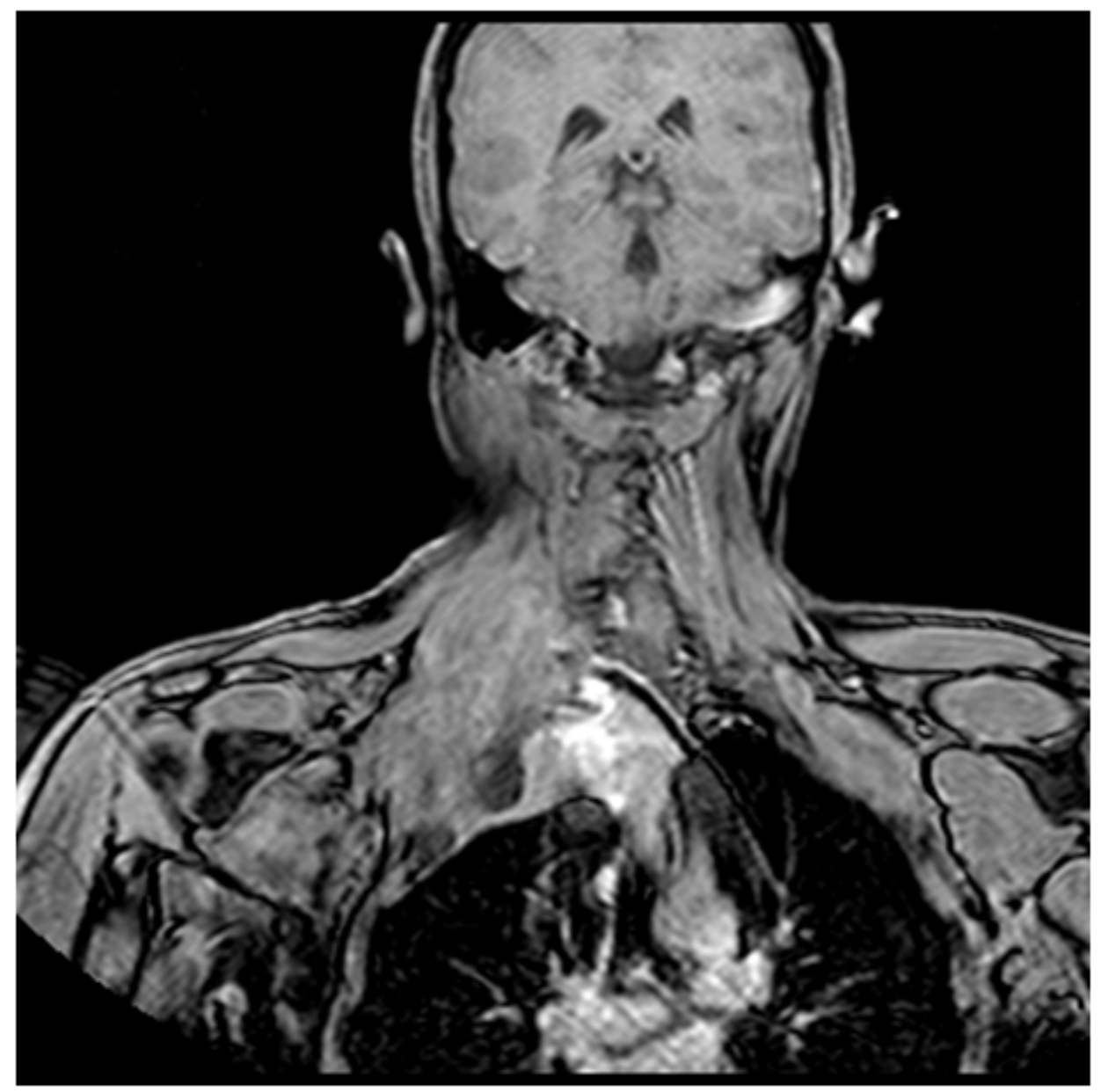

Figura 5: Ressonância magnética do pescoço, evidenciando realce pelo meio de contraste paramagnético na sequência THRIVE.

locus (APC). ${ }^{6}$ Há múltiplos espectros de expressão das alterações genéticas a depender da localização da mutação no gene, havendo, por conseguinte, diferentes fenótipos associados. ${ }^{2,7}$

O padrão de hereditariedade é autossômico dominante e a penetrância do fenótipo gastrointestinal é virtualmente de $100 \%$, enquanto que as manifestações extraintestinais têm penetrância variável e não têm relação com a quantidade de pólipos. ${ }^{6,7,8}$ No presente relato, não foi identificado padrão hereditário nos antecedentes familiares da paciente, a qual deve fazer parte dos $20 \%$ dos casos representam mutações de novo, sem história familiar. ${ }^{6}$

Usualmente, o aparecimento das lesões de partes moles ocorre nas primeiras duas décadas de vida, sendo frequentemente a primeira manifestação da síndrome. As lesões superficiais de partes moles podem representar cistos de inclusão epidérmica, fibromas, lipomas ou tumores desmóides, sendo que os cistos epidermóides são as mais prevalentes, estes últimos presentes em $50-65 \%$ dos pacientes. ${ }^{1,2,3,6}$

Os tumores de partes moles apresentam-se como massas hipocelulares com bandas de colágeno de distribuição e densidade variáveis. O estudo e descrição anatomopatológica destas lesões fibrosas ainda é inconsistente, de forma que lesões virtualmente semelhantes podem ter diferentes nomenclaturas (por exemplo: tumor desmóide, fibromatose congênita, fibroma). ${ }^{2}$ É interessante observar que um mesmo paciente pode apresentar múltiplas lesões com características microscópicas distintas. ${ }^{5}$

O tumor desmóide, achado extraintestinal de maior relevância clínica na paciente em questão, é 
uma lesão fibrosa benigna, porém localmente agressiva, com predomínio na parede abdominal ou mesentério. Origina-se de estruturas musculoaponeuróticas, ${ }^{9}$ não possui cápsula e potencialmente infiltra tecido muscular e fáscias adjacentes, com baixo potencial de metastatização. 6,10

O crescimento tumoral sofre influência hormonal pelo estrogênio, sendo o tumor desmóide mais frequente em pacientes do sexo feminino, ${ }^{10}$ como no presente caso. Estima-se prevalência de $8,9 \%$ nos pacientes com PAF, sendo que estes pacientes apresentam risco 1000 vezes maior de desenvolver tumor desmóide que a população geral.6,11

História de trauma, cirúrgico ou não, frequentemente precede $\mathrm{o}$ aparecimento das massas de partes moles, de forma que sua emergência em sítios de cicatriz não é incomum. ${ }^{12} \mathrm{~A}$ reação fibroblástica desencadeada pelo ato cirúrgico é responsável por recorrência de $40 \%$ dos casos dos tumores excisionados, devendo-se restringir a abordagem operatória às lesões sintomáticas. ${ }^{10}$

A paciente relatada apresentou sintomatologia associada ao tumor desmóide devido à compressão extrínseca de estruturas vasculonervosas na região cervico-torácica à direita. Em casos como este, deve-se ponderar os riscos e benefícios de uma abordagem cirúrgica, considerando-se, também, a alta taxa de recidiva local.

Quanto ao acometimento ósseo, a paciente relatada exemplifica o predomínio de osteomas nos ossos da face, especialmente mandíbula e seios paranasais, como estabelecido na literatura. Estas lesões, presentes em cerca de $50 \%$ dos pacientes, usualmente precedem o diagnóstico de polipose intestinal e se caracterizam por massa assintomática de crescimento progressivo. ${ }^{3,5,6,11,13} \mathrm{O}$ desenvolvimento e o curso clínico dos osteomas não apresentam relação direta com a evolução dos pólipos gastrointestinais ou neoplasia colônica. ${ }^{13}$ Apesar de haver relatos de evolução para malignidade, a abordagem dos osteomas pode ser necessária por motivos estéticos ou clínicos. ${ }^{3,13}$
As lesões intestinais caracterizam-se por pólipos de distribuição difusa predominando nas alças colônicas, mais frequentemente adenomas. ${ }^{6}$ Têm pico de diagnóstico aos 22 anos e possuem taxa de progressão para malignidade tão alta quanto $100 \%{ }^{1,2,3,6} \mathrm{~A}$ idade média de diagnóstico de neoplasia colônica nestes pacientes é de 39,2 anos. ${ }^{12}$ Os pólipos gástricos são mais usualmente pólipos de glândulas fúndicas, como visto no presente caso, com baixo potencial maligno. Já os pólipos duodenais apresentam alto risco de malignização. ${ }^{14} \mathrm{~A}$ paciente deste estudo teve diagnóstico de polipose gastrointestinal aos 30 anos, apresentando atipias nas biópsias a partir dos 32 anos.

A colectomia total pode ser considerada, mas não tem valor curativo, pois estes pacientes têm alto risco de desenvolvimento de outras neoplasias, como tumores periampulares, neoplasia de intestino delgado e tumor papilífero de tireóide. ${ }^{11,15}$

\section{Conclusão}

Os fibromas relacionados a Gardner e os tumores ósseos constituem importante alerta clínico de Síndrome de Gardner subjacente, usualmente precedendo as manifestações intestinais. ${ }^{11}$ Não obstante sejam majoritariamente benignos, as lesões ósseas e de partes moles podem ser localmente agressivos, ocasionar sintomas compressivos e perturbação estética.

Apesar de inespecíficos quando avaliados isoladamente, o conjunto dos achados radiológicos e clínicos de polipose múltipla gastrointestinal e manifestações extraintestinais torna o diagnóstico sugestivo, permitindo abordagem precoce da doença e reduzindo morbimortalidade destes pacientes.

Salienta-se, ainda, a importância da investigação familiar precoce, tendo-se em vista que $80 \%$ dos casos de Síndrome de Gardner são hereditários com penetrância completa. 


\section{Referências}

1. Duncan BR, Dohner VA, Priest JH. The Gardner syndrome: Need for early diagnosis. J Pediatr. 1968; 72: 497-505.

2. Wehrli BM, Weiss SW, Yandow S, Coffin C. Gardner-associated fibromas (GAF) in young patients: a distinct fibrous lesion that identifies unsuspected Gardner syndrome and risk for fibromatosis. Am J Surg Pathol. 2001; 25:645-51.

3. Bilkay U, Erdem O, Ozek C, Helvaci E, Kilic K, Ertan $Y$, Gurler T. Benign osteoma with Gardner syndrome: review of the literature and report of a case. J Craniofac Surg. 2004; 15:506-9.

4. Bülow S, Faurschou Nielsen T, Bülow C, Bisgaard ML, Karlsen $L$, Moesgaard $F$. The incidence rate of familial adenomatous polyposis. Results from the Danish Polyposis Register. Int Colorectal Dis. 1996; 11:88-91.

5. Gardner EJ, Richards RC. Multiple cutaneous and subcutaneous lesions occurring simultaneously with hereditary polyposis and osteomatosis. Am J Hum Genet. 1953; 5: 139-47.

6. Butler J, Healy C, Toner M, Flint S. Gardner syndrome review and report of a case, In: Oral Oncology Extra, Volume 41, Issue 5, 2005, Pages 89-92, ISSN 1741-9409. https://doi.org/10.1016/j.ooe.2005.02.001.

7. Bisgaard ML, Bülow S. Familial adenomatous polyposis (FAP): genotype correlation to FAP phenotype with osteomas and sebaceous cysts. Am J Med Genet A. 2006; $140: 200-4$.
8. Jasperson KW, Patel SG, Ahnen DJ. APC-Associated Polyposis Conditions. 1998 Dec 18 [Updated 2017 Feb 2]. In: Adam MP, Ardinger HH, Pagon RA, et al., editors.

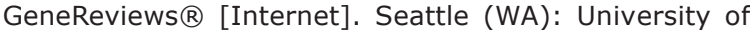
Washington, Seattle; 1993-2017.

9. Heiskanen I, Järvinen HJ. Occurrence of desmoid tumours in familial adenomatous polyposis and results of treatment. Int J Colorectal Dis. 1996; 11: 157-62.

10. Rodriguez-Bigas MA, Mahoney MC, Karakousis CP, Petrelli NJ. Desmoid Tumors in Patients with Familial Adenomatous Polyposis. Cancer. 1994;74:1270-4.

11. Tsui YK, Wu RH, Tzeng CC, Wu TC, Chen TY, Wu TC, Tzeng WS. A young Female Patient with Gardner Syndrome: a case report. Chin J Radiol 2008; 33: 51-56

12. Gorlin RJ, Chaudhry AP. Multiple osteomatosis, fibromas, lipomas and fibrosarcomas of the skin and mesentery, epidermoid inclusion cysts of the skin, leiomyomas and multiple intestinal polyposis. A heritable disorder of connective tissue. $\mathrm{N}$ Engl J Med 1960; 263:1151-8.

13. Takeuchi Y, Takenoshita K, Kubo M, Iida M. Natural course of jaw lesions in patients with familial adenomatosis coli (Gardner's syndrome). Int J Oral Maxillofac Surg, 22 (1993), pp. 226-230

14. Lynch HT, Fitzgibbons R Jr.. Surgery, desmoid tumors, and familial adenomatous polyposis: case report and literature review. Am J Gastroenterol. 1996; 91: 2598-601.

15. Newman CA, Reuthe WL, Wakabayashi MN, Payette MM, Plavsic BM. Gastrointestinal case of the day. Gardner syndrome. Radiografia. 1999; 19: 546-8. 